\section{Conditioned taste aversion in anesthetized rats: A reply to Burešová and Bureš}

\author{
BERNARD M. RABIN \\ University of Maryland Baltimore County \\ and \\ JOAN S. RABIN \\ Towson State University, Baltimore, Maryland
}

In their comment on the paper by B. M. Rabin and J. S. Rabin (1984), Burešová and Bureš (1986) suggest that the reported controversy concerning whether or not an $\mathrm{LiCl}$ induced taste aversion can be acquired by anesthetized rats is more apparent than real. On the basis of the additional information included in their note, indicating that the rats in their Experiment 1 were anesthetized immediately after drinking the CS and maintained under anesthesia while receiving the $\mathrm{LiCl}$ injection, we would certainly concur with that conclusion.

However, nowhere in the original description of their Experiment 1 do Burešová and Bureš (1977) indicate that their rats were anesthetized when the $\mathrm{LiCl}$ was administered. Rather, they simply state that the rats were maintained under anesthesia for the 5-h CS-US interval, a procedure similar to that used by Rozin and Ree (1972). The manner in which Burešová and Bureš (1977) described their procedure, particularly when combined with the procedural diagram presented in their Figure 1, suggests that the $\mathrm{LiCl}$ was not administered until the rats had recovered from the anesthetic. This interpretation is strengthened by the fact that in their discussion of the results they refer to the results reported by Rozin and Ree (1972), who administered both CS and US to awake animals, but fail to mention any similarity between their results and those obtained by Roll and Smith (1972). As a result, we did not cite Burešová and Bureš's Experiment 1 because, given the description, it did not appear to be relevant.

Similarly, we chose to reference only the papers that

B. M. Rabin's mailing address is: Department of Psychology, University of Maryland Baltimore County, Catonsville, MD 21228. specifically dealt with the role of anesthetics on the $a c$ quisition of a taste aversion. The paper by Millner and Palfai (1975) was omitted because of several procedural difficulties that confound the interpretation of the results as they relate to the use of Nembutal. First, in the only Nembutal group, which was included only as a control group for the metrazol treatments, the anesthetic was administered immediately after the $\mathrm{LiCl}$, so that there is a possibility that the rats did experience the US before the anesthetic took complete effect. Second, since the administration of Nembutal can cause a CTA (Rabin \& Rabin, unpublished results), it is not clear whether the results obtained with Nembutal by Millner and Palfai resulted from the $\mathrm{LiCl}$ or Nembutal injection.

In summary, our report (Rabin \& Rabin, 1984) of potentially conflicting findings concerning the effects of anesthesia on the acquisition of radiation- and $\mathrm{LiCl}$ induced taste aversions was based upon the published record, and what now appears to be an incomplete description of Burešová and Bureš (1977) methods. On the basis of the additional procedural information provided by Burešová and Bureš (1986) in their note, we would agree that the results of our respective studies are in accord.

\section{REFERENCES}

Burešoví, O., \& BurEš, J. (1977). The effect of anesthesia on acquisition and extinction of conditioned taste aversion. Behavioral Biology, 20, 41-50.

Burešová, O., \& BUREŠ, J. (1986). Conditioned taste aversion in anesthetized rats: A nonexistent controversy. Animal Learning \& Behavior, 14, 452.

Millner, J. R., \& Palfai, T. (1975). Metrazol impairs conditioned aversion produced by LiCl: A time-dependent effect. Pharmacology, Biochemistry \& Behavior, 3, 201-204.

RABIN, B. M., \& RABIN, J. S. (1984). Acquisition of radiation- and lithium chloride-induced conditioned taste aversions in anesthetized rats. Animal Learning \& Behavior, 12, 439-441.

Roll, D. L., \& Sith, J. C. (1972). Conditioned taste aversion in anesthetized rats. In M. E. P. Seligman \& J. L. Hager (Eds.), Biological foundations of learning. New York: Appleton-Century-Crofts. RozIN, P., \& REE, P. (1972). Long extension of effective CS-US-CS interval by anesthesia between CS and US. Journal of Comparative \& Physiological Psychology, 80, 43-48.

(Manuscript received June 17, 1986; accepted for publication June 17, 1986.) 